\title{
Somatostatin receptor 5 and cannabinoid receptor 1 activation inhibit secretion of glucose-dependent insulinotropic polypeptide from intestinal $K$ cells in rodents
}

\author{
C. E. Moss - W. J. Marsh - H. E. Parker • \\ E. Ogunnowo-Bada • C. H. Riches - A. M. Habib • \\ M. L. Evans • F. M. Gribble • F. Reimann \\ Received: 26 April 2012 / Accepted: 3 July 2012 /Published online: 8 August 2012 \\ (C) The Author(s) 2012. This article is published with open access at Springerlink.com
}

\begin{abstract}
Aims/hypothesis Glucose-dependent insulinotropic polypeptide (GIP) is an enteroendocrine hormone that promotes storage of glucose and fat. Its secretion from intestinal $\mathrm{K}$ cells is triggered by nutrient ingestion and is modulated by intracellular cAMP. In view of the proadipogenic actions of GIP, this study aimed to identify pathways in $\mathrm{K}$ cells that lower cAMP levels and GIP secretion.

Methods Murine K cells purified by flow cytometry were analysed for expression of $\mathrm{G}_{\alpha \mathrm{i}}$-coupled receptors by transcriptomic microarrays. Somatostatin and cannabinoid receptor expression was confirmed by quantitative RT-PCR. Hormone secretion in vitro was measured in GLUTag and primary murine intestinal cultures. cAMP was monitored in GLUTag cells using the genetically encoded sensor Epac2-camps. In vivo tolerance tests were performed in cannulated rats.

Results Purified murine K cells expressed high mRNA levels for somatostatin receptors (Sstrs) Sstr2, Sstr3 and Sstr5,
\end{abstract}

Electronic supplementary material The online version of this article (doi:10.1007/s00125-012-2663-5) contains peer-reviewed but unedited supplementary material, which is available to authorised users.

C. E. Moss · H. E. Parker · A. M. Habib · F. M. Gribble $(\bowtie) \cdot$

F. Reimann $(\bowtie)$

Cambridge Institute for Medical Research,

Wellcome Trust/MRC Building, Addenbrooke's Hospital,

Box 139, Hills Road,

Cambridge CB2 0XY, UK

e-mail: fmg23@cam.ac.uk

e-mail: fr222@cam.ac.uk

W. J. Marsh • E. Ogunnowo-Bada • C. H. Riches • M. L. Evans Cambridge Metabolic Research Laboratories and Department of Medicine, Addenbrooke's Hospital,

Hills Road,

Cambridge, UK and cannabinoid receptor type $1(\mathrm{Cnr} 1, \mathrm{CB} 1)$. Somatostatin inhibited GIP and glucagon-like peptide-1 (GLP-1) secretion from primary small intestinal cultures, in part through SSTR5, and reduced cAMP generation in GLUTag cells. Although the CB1 agonist methanandamide (mAEA) inhibited GIP secretion, no significant effect was observed on GLP-1 secretion from primary cultures. In cannulated rats, treatment with mAEA prior to an oral glucose tolerance test suppressed plasma GIP but not GLP-1 levels, whereas the CB1 antagonist AM251 elevated basal GIP concentrations.

Conclusions/interpretation GIP release is inhibited by somatostatin and CB1 agonists. The differential effects of CB1 ligands on GIP and GLP-1 release may provide a new tool to dissociate secretion of these incretin hormones and lower GIP but not GLP-1 levels in vivo.

Keywords Cannabinoid receptor · Cannabinoid receptor type 1 . Glucose-dependent insulinotropic polypeptide . Glucagon-like peptide-1 $\cdot$ K cells $\cdot$ Somatostatin

$\begin{array}{ll}\text { Abbreviations } \\ \text { CB1 } & \text { Cannabinoid receptor type 1 } \\ \text { CFP } & \text { Cyan fluorescent protein } \\ \text { CNS } & \text { Central nervous system } \\ \mathrm{C}_{\mathrm{t}} & \text { Cycle threshold } \\ \text { FRET } & \text { Förster resonance energy transfer } \\ \text { GIP } & \text { Glucose-dependent insulinotropic polypeptide } \\ \text { GLP-1 } & \text { Glucagon-like peptide-1 } \\ \text { IBMX } & \text { Isobutylmethylxanthine } \\ \text { mAEA } & \text { Methanandamide } \\ \text { RMA } & \text { Robust multichip average } \\ \text { SGLT1 } & \text { Sodium-dependent glucose transporter 1 } \\ \text { SSTR } & \text { Somatostatin receptor } \\ \text { SSTR5A } & \text { SSTR5 antagonist } \\ \text { YFP } & \text { Yellow fluorescent protein }\end{array}$




\section{Introduction}

Glucose-dependent insulinotropic polypeptide (GIP) is a hormone from the proximal small intestine that is secreted in response to food ingestion [1]. Although it acts as an incretin hormone to promote insulin secretion, mice lacking GIP receptors show only a mild impairment of postprandial glucose homeostasis [2], but appear to be protected from the obesogenic effects of either a high-fat diet or the hyperphagic leptin deficient $o b / o b$ background [3]. Similar amelioration of diet-induced obesity, with correspondingly improved insulin sensitivity, was observed in other mouse models with impaired GIP signalling due to treatment with a GIP-receptor antagonist (Pro ${ }^{3}$-GIP) [4] or ablation of GIP-secreting K cells [5]. These results have been used to argue that inhibiting GIP signalling may have beneficial effects in obese individuals [6]. A similar outcome could potentially be achieved by reducing GIP secretion.

GIP release is triggered by the arrival of nutrients in the upper small intestine, where it is produced by enteroendocrine $\mathrm{K}$ cells located predominantly in the duodenal epithelium [1]. These are an open-type endocrine cell, with apical surfaces facing into the gut lumen, capable of directly sampling the luminal contents $[7,8]$. They are stimulated by a variety of nutrients, including monosaccharides and fats [1,9]. Glucose sensing involves uptake by the sodium-dependent glucose cotransporter 1 (SGLT1), a sodium-coupled transporter, as exemplified by the loss of glucose-triggered GIP secretion in SGLT1-deficient mice [10]. The electrogenic SGLT1 signal, however, operates synergistically with cytosolic cAMP levels [11], providing opportunities for G-protein-coupled receptor pathways to influence GIP release. The expression of the $\mathrm{G}_{\alpha \mathrm{s}}{ }^{-}$ coupled receptor Gprl19 in K cells, for example, may contribute to fat-dependent GIP secretion via the locally generated ligands 2-mono-oleoyl glycerol and oleoylethanolamide, produced by luminal triacylglycerol digestion and local tissue metabolism, respectively $[12,13]$. Relatively little is known about inhibitory signals that reduce cAMP levels in $\mathrm{K}$ cells, mediated by $\mathrm{G}_{\alpha \mathrm{i}}$-coupled receptors.

Transgenic mice producing the yellow fluorescent protein (YFP) Venus under the control of the GIP promoter have provided a new tool for identifying and purifying $\mathrm{K}$ cells for transcriptomic and functional analysis [11]. Here we report that the expression of Sstr 5 and the cannabinoid receptor type 1 (Cnrl, CB1), examples of predominantly $\mathrm{G}_{\alpha \mathrm{i}}$-coupled receptors, is enriched in $\mathrm{K}$ cells and that these receptors can be targeted to manipulate GIP secretion.

\section{Methods}

Animal models Animal procedures were approved by the local ethics committee and conformed to UK Home Office regulations. All mice used in the experiments were on a C57BL/6 background and housed in individually ventilated cages. Male Sprague Dawley rats were purchased from Charles River (Margate, UK) and housed in conventional caging.

Expression analysis $\mathrm{K}$ and $\mathrm{L}$ cells were isolated by FACS from GIP-Venus [11] and GLU-Venus [14] transgenic mice, respectively, as previously described. Briefly, small intestine (upper $10 \mathrm{~cm}$ ) or colon was digested as described below for primary cultures, but using a higher collagenase concentration of $1 \mathrm{mg} / \mathrm{ml}$ in Hank's buffered salt solution (HBSS), to obtain single cells. Cell suspensions were separated using a MoFlo Cytomation sorter (Beckman Coulter, High Wycombe, UK) (488 nm excitation) to obtain populations of Venus-positive or Venus-negative cells, which were collected directly into lysis buffer for mRNA extraction. Purified $\mathrm{K}$ and $\mathrm{L}$ cell populations were over $95 \%$ pure as assessed by fluorescence microscopy, and were enriched more than 2,000-fold for GIP and glucagonlike peptide-1 (GLP-1) concentrations, respectively, compared with non-fluorescent cells, as assessed by ELISA [11, 14].

RNA was extracted using a microscale RNA isolation kit (Applied Biosystems, Warrington, UK) as previously described $[11,14]$. GLUTag cell RNA was isolated using TRI reagent. For hybridisation to mouse 4302.0 arrays GeneChips (Affymetrix UK, High Wycombe, UK), RNA underwent two rounds of amplification based on in vitro translation from a T7 promoter introduced during oligo dT-priming (Two-cycles cDNA Synthesis Kit, Affymetrix UK; MEGAscript T7 kit, Ambion, Austin, TX, USA), and expression levels of each probe were determined by robust multichip average (RMA) analysis. Quantitative PCR was performed with cDNA reverse-transcribed from nonamplified RNA on a 7900 HT Fast Real-Time PCR system (Applied Biosystems, Foster City, CA, USA) using a QuantiTect SYBR Green PCR mix (Qiagen, Crawley, UK) and the primers given in Table 1.

In all cases, expression was compared with that of $\beta$-actin measured on the same sample in parallel on the same plate, giving a cycle threshold $\left(\mathrm{C}_{\mathrm{t}}\right)$ difference $\left(\Delta \mathrm{C}_{\mathrm{t}}\right)$ for $\beta$-actin minus the test gene. $C_{t}$ s for $\beta$-actin ranged from 20 to 25 in the different samples, and reactions in which the test gene was undetectable were assigned a $C_{t}$ value of 40 . A $\Delta \mathrm{C}_{\mathrm{t}}$ value of -12 to -15 is, therefore, close to the detection limit of the assay. Mean, SEM and statistics were performed on the $\Delta \mathrm{C}_{\mathrm{t}}$ data and only converted to relative expression levels $\left(2^{\Delta \mathrm{C}_{\mathrm{t}}}\right)$ for presentation in the figures.

Primary murine intestinal cultures Mice aged 2-6 months were killed by cervical dislocation and the guts collected into ice-cold Leibovitz-15 (L-15) medium (PAA, Yeovil, UK). Mixed intestinal cultures were produced, as previously described $[11,14]$. Briefly, the intestine was opened longitudinally, rinsed in PBS and chopped into 1-2 mm pieces. 
Table 1 Amplicon length and sequences of primers used in SYBR green analysis

\begin{tabular}{|c|c|c|}
\hline Gene & $\begin{array}{l}\text { Amplicon } \\
\text { length }\end{array}$ & Primer sequence $5^{\prime}-3^{\prime}$ \\
\hline$C N R 1$ & $166 \mathrm{bp}$ & $\begin{array}{l}\text { fwd: GAGCAAGGACCTGAGACATGC } \\
\text { rev: CTTAACAGTGCTCTTGATGCAGC }\end{array}$ \\
\hline$C N R 2$ & $150 \mathrm{bp}$ & $\mathrm{Mm} \_\mathrm{Cnn} 2 \_1 \_\mathrm{SG}$ \\
\hline SSTR2 & $150 \mathrm{bp}$ & Mm_Sstr2_2_SG \\
\hline SSTR3 & $223 \mathrm{bp}$ & $\begin{array}{l}\text { fwd: ATGGCCACTGTTACCTATCCTTC } \\
\text { rev: GGATATAGACACTGGTCACTGATGG }\end{array}$ \\
\hline SSTR5 & $442 \mathrm{bp}$ & $\begin{array}{l}\text { fwd: GTCACTAGTGGACCCGGTG } \\
\text { rev: AGAGCGGCAGAGACATGAG }\end{array}$ \\
\hline Actb & $149 \mathrm{bp}$ & Mm_Actb_1_SG \\
\hline
\end{tabular}

Where the sequence is unknown the product number of the QuantiTect primer assay is given

Upper small intestinal cultures were derived from 10 $15 \mathrm{~cm}$ of intestine immediately distal to the stomach, and colon cultures included tissue distal to the caecum. Tissue was digested three or four times with $0.4 \mathrm{mg} / \mathrm{ml}$ collagenase XI, centrifuged at $300 \mathrm{~g}$, and resuspended in DMEM (25 mmol/l glucose) supplemented with $10 \%$ (vol/vol) FBS, 2 mmol/l L-glutamine, 100 units $/ \mathrm{ml} \mathrm{pen-}$ icillin and $0.1 \mathrm{mg} / \mathrm{ml}$ streptomycin. Cell/crypt suspensions were plated onto 24-well plates coated with a thin film of Matrigel (BD Bioscience, Oxford, UK) and incubated at $37^{\circ} \mathrm{C}$ in $5 \% \mathrm{CO}_{2}$.

Cell line culture GLUTag cells were cultured in DMEM (5.6 mmol/l glucose) supplemented with $10 \%$ (vol/vol) FBS, $2 \mathrm{mmol} / \mathrm{l}$ L-glutamine, 100 units $/ \mathrm{ml}$ penicillin and $0.1 \mathrm{mg} / \mathrm{ml}$ streptomycin, at $37^{\circ} \mathrm{C}$ in $5 \% \mathrm{CO}_{2}$.

Secretion studies Around 20-24 h after cell plating, wells were washed thoroughly with bath solution before being incubated for $2 \mathrm{~h}$ at $37^{\circ} \mathrm{C}$ with test reagents in bath solution supplemented with $0.1 \%$ BSA. Five hundred KIU/ml aprotinin, $10 \mu \mathrm{mol} / 1$ amastatin and $0.1 \mathrm{mmol} / 1$ diprotin A were added to wells planned for GLP-1 assay. The supernatants were collected and briefly centrifuged before measuring the hormone content. Primary cultures were subsequently treated with lysis buffer containing $50 \mathrm{mmol} / \mathrm{l}$ Tris- $\mathrm{HCl}$, $150 \mathrm{mmol} / 1 \mathrm{NaCl}, 1 \%$ IGEPAL-CA 630, 0.5\% deoxycholic acid and one tablet of complete EDTA-free protease inhibitor cocktail (Roche Dignostics, Burgess Hill, UK). Cells were mechanically disrupted to extract intracellular peptides. GLP-1, GIP and/or somatostatin were assayed in supernatant fractions and cell extracts from primary intestinal cultures, and in supernatant fractions from GLUTag cells by ELISA (GLP-1 active ELISA kit, GIP Total ELISA kit, Millipore, USA; Somatostatin ELISA Kit, Phoenix Pharmaceuticals, Burlingame, CA, USA).
Hormone secretion from primary cultures was expressed as a fraction of the total hormone measured in each well and normalised to the basal secretion measured in parallel on the same day. Rates of hormone secretion from primary cultures under basal conditions were $5.1 \pm 0.7 \mathrm{pg}$ well ${ }^{-1} 2 \mathrm{~h}^{-1}$ (GIP, $n=47$ ), $1.7 \pm 0.1 \mathrm{fmol}^{\mathrm{well}}{ }^{-1} 2 \mathrm{~h}^{-1}$ (GLP-1 from small intestinal cultures, $n=37$ ) and $3.9 \pm 0.6 \mathrm{fmol}^{\mathrm{well}}{ }^{-1} 2 \mathrm{~h}^{-1}$ (GLP-1 from colonic cultures, $n=9$ ), which was equivalent to $2.2 \pm 0.2 \%, 6.3 \pm 0.4 \%$ and $3.0 \pm 0.3 \%$ of the content being released in $2 \mathrm{~h}$, respectively. Secretion from GLUTag cells was normalised to control wells from the same plate. Each condition was tested in three or four wells per 24-well plate, so the number of individual experiments can be estimated by dividing the numbers above the bars by 3 or 4 .

\section{cAMP Förster resonance energy transfer measurements} Single-cell measurements of cAMP levels were made using the Förster resonance energy transfer (FRET)-based sensor Epac2-camps [15]. GLUTag cells were seeded in $6 \mathrm{~cm}$ Matrigel-coated plastic dishes and, when 80-90\% confluent, were transfected with $3 \mu \mathrm{g}$ Epac2-camps DNA probe and $15 \mu$ l Lipofectamine 2000 (Invitrogen, Paisley, UK) for $24 \mathrm{~h}$. Cells were trypsinised and re-seeded onto Matrigel-coated $35 \mathrm{~mm}$ glass-bottomed dishes (Mattek Corporation, Ashland, MA, USA) for experiments 24$48 \mathrm{~h}$ later.

Cells, continuously perfused with bath solution supplemented with $0.1 \%$ BSA with or without test reagents, were visualised with a $\times 40$ oil immersion objective on an inverted microscope (Olympus IX71, Southend on Sea, UK). Excitation at $435 \mathrm{~nm}$ was achieved using a xenon arc lamp coupled to a monochromator (Cairn Research, Faversham, UK) controlled by MetaFluor software (Molecular Devices, Wokingham, UK). Cyan fluorescent protein (CFP) emission at $470 \mathrm{~nm}$ and YFP emission at $535 \mathrm{~nm}$ were monitored using an Optosplit II beam splitter (Cairn Research) and an Orca-ER digital camera (Hamamatsu, Welwyn Garden City, UK), and expressed as the CFP/YFP fluorescence ratio [16]. Maximum ratios were determined at baseline and following test reagent application, and calculated increments were normalised to that triggered by the first forskolin application. No significant differences in the response (by ANOVA) were observed with recurrent forskolin applications.

Oral glucose tolerance test Male Sprague Dawley rats (Charles River, Margate, UK) underwent surgical placement of a single right jugular vein catheter as previously described [17], and were allowed to recover for 4-5 days. Only animals that had regained their preoperative body weight with no signs of infection were allowed to proceed to the study. On the day of study, overnight-fasted rats were acclimatised to the study room and caging for 
an hour prior to experimentation. A total of $30 \mathrm{~min}$ before the OGTT, rats in the methanandamide (mAEA) study were dosed intraperitoneally with either mAEA (at a dose of $10 \mathrm{mg} / \mathrm{kg}$, as previously described [18]) suspended in Tocrisolve $(1 \mathrm{ml} / \mathrm{kg})$ or an equal volume of Tocrisolve alone. In the AM251 study, rats were dosed intraperitoneally with either vehicle control (lacking only $\mathrm{AM} 251$ ) or $4 \mathrm{mg} / \mathrm{kg}$ of the CB1 antagonist AM251 made up in DMSO, and dissolved in Tween 80 and normal saline in a 1:1:8 ratio, with an injection volume of $1 \mathrm{ml} / \mathrm{kg}$ [19]. An oral gavage of $2 \mathrm{~g} / \mathrm{kg}$ glucose and $100 \mathrm{mg} / \mathrm{kg}$ acetaminophen dissolved in PBS $(10 \mathrm{ml} / \mathrm{kg})$ was administered at $t=0$. Blood samples of $0.5 \mathrm{ml}$ were taken at $-30,0,5,15$ and $30 \mathrm{~min}$ after gavage. Blood was collected into tubes containing $4 \mu \mathrm{l}$ EDTA and immediately spun for $90 \mathrm{~s}$. Plasma glucose was analysed by Analox GM9 (Analox Instruments, London, UK); samples for GIP, GLP-1, insulin and acetaminophen were snap-frozen for later analysis. Plasma GIP was measured by ELISA (GIP Total ELISA Kit; Millipore, Watford, UK), total GLP-1 and insulin by immunoassay (MesoScale Discovery, Gaithersburg, MD, USA), and acetaminophen by colorimetric detection of p-aminophenol (Siemens, Camberley, UK). Rats were killed by overdose of anaesthesia immediately after the 30 min sample had been taken.

Solutions and chemicals The bath solution contained (in mmol/l) $138 \mathrm{NaCl}, 4.5 \mathrm{KCl}, 4.2 \mathrm{NaHCO}_{3}, 1.2 \mathrm{NaH}_{2} \mathrm{PO}_{4}$, 2.6 $\mathrm{CaCl}_{2}, 1.2 \mathrm{MgCl}_{2}, 10$ HEPES, 10 glucose. Unless stated, all drugs and chemicals were obtained from Sigma (Poole, UK) and, where possible, drugs were made up as $1,000 \times$ stock. The mAEA (Tocris, Bristol, UK) was dissolved in ethanol for in vitro and Tocrisolve (Tocris) for in vivo studies. Somatostatin-14 was dissolved in water. AM251 (Tocris) and the SSTR5 antagonist, referred to as SSTR5A (Compound A described in [20]; a kind gift from F. Hoffmann-La Roche AG, Basel, Switzerland) were dissolved in DMSO.

Data analysis Comparisons between conditions were made using Student's $t$ test (Microsoft Excel) or by one or two-way ANOVA with post hoc Bonferroni test (Prism5, GraphPad, La Jolla, CA, USA), with a threshold for significance of $p<0.05$. All data are expressed as mean \pm SEM.

a

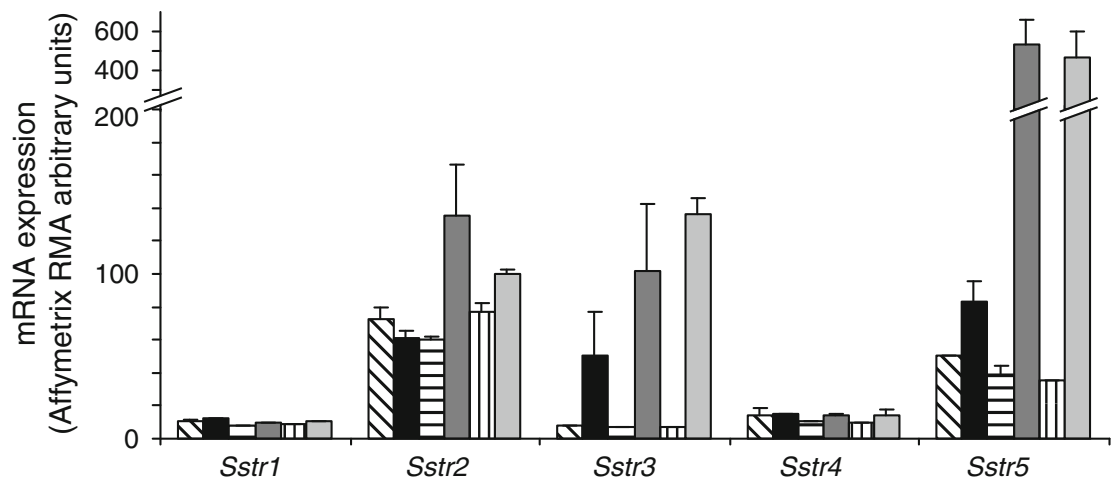

b

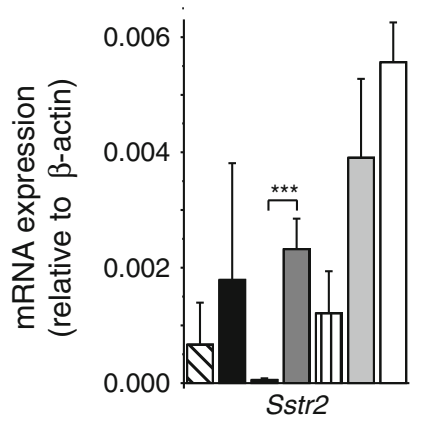

C

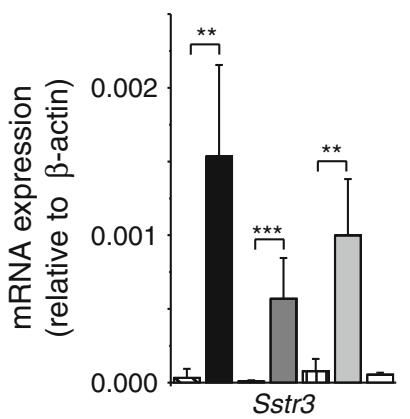

d

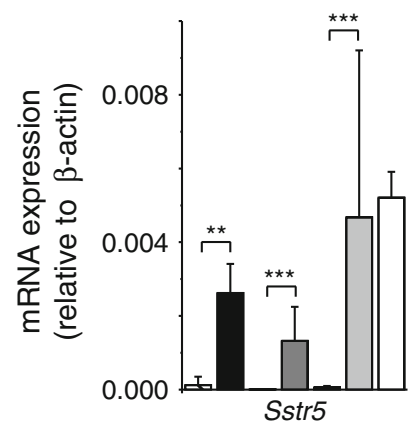

Fig. 1 Enteroendocrine cells express Sstr2, Sstr 3 and Sstr 5. (a) Mean microarray RMA intensities for probes against Sstr $1-S s t r 5$ in $\mathrm{K}$ cells $(\mathrm{K}+$, black bars), small intestinal and colonic $\mathrm{L}$ cells $(\mathrm{L}+$, dark grey bars; $\mathrm{LC}+$, light grey bars, respectively) and non-fluorescent control cells from the same tissue preparations $(\mathrm{K}-$, diagonal hatching; $\mathrm{L}-$, horizontal hatching; $\mathrm{LC}-$, vertical hatching) ( $n=2-3$ each). (b-d) Relative expression of Sstr2 (b),
Sstr3 (c) and Sstr 5 (d) mRNA relative to $\beta$-actin assessed by RT-PCR in FACS-sorted cell populations labelled as in (a) plus GLUTag cells (white bars). Data are presented as the geometric mean and upper SEM $(n>3$ each). Significance comparisons between $\mathrm{K}+$ and $\mathrm{K}-, \mathrm{L}+$ and $\mathrm{L}-$, and $\mathrm{K}+$ and $\mathrm{L}+$ cells were calculated by one-way ANOVA with post hoc Bonferroni test performed on the $\log ($ base 2 ) data: $* * p<0.01, * * * p<0.001$ 


\section{Results}

Expression of Sstr 3 and Sstr 5 mRNA is enriched in $K$ cells To identify $\mathrm{G}_{\alpha \mathrm{i}}$-coupled receptors expressed in incretin-secreting cells, FACS-purified $\mathrm{K}$ and $\mathrm{L}$ cells from GIP-Venus and GLU-Venus mice, respectively, together with control (non-fluorescent) cells were analysed by microarray. Consistent with the previously observed inhibition of GIP secretion by somatostatin [21], we detected signals for Sstr2, Sstr3 and Sstr 5 in enteroendocrine cell populations (Fig. 1a). Quantitative PCR using nonamplified mRNA from additional FACS-sorted cells similarly showed enrichment of Sstr 3 and Sstr 5 in enteroendocrine cell populations (Fig. 1b). Sstr5, but not Sstr3, expression was also observed in the colon-derived $\mathrm{L}$ cell model line GLUTag.

Somatostatin inhibits cAMP elevation partially through SSTR5 activation As SSTRs are believed to couple predominantly via $\mathrm{G}_{\alpha \mathrm{i}}$, we aimed to confirm an effect of SSTR activation on intracellular cAMP levels. Repeated applications of forskolin $(2 \mu \mathrm{mol} / \mathrm{l})$ to GLUTag cells resulted in acute elevations of cytosolic cAMP, as monitored in single cells producing an Epac-based FRET sensor [16]. Concomitant application of somatostatin resulted in a profound and reversible suppression of the forskolin-triggered cAMP response (Fig. 2a), which was partially reversed by coapplication of a selective SSTR5 antagonist, SSTR5A (Fig. 2b).

SSTR5 underlies somatostatin-dependent inhibition of GIP and GLP-1 secretion in primary culture GIP secretion from $\mathrm{K}$ cells in mixed primary small intestinal cultures was stimulated $2.5 \pm 0.3$-fold by incubation with the non-specific phosphodiesterase inhibitor isobutylmethylxanthine (IBMX; $100 \mu \mathrm{mol} / \mathrm{l})$, presumably reflecting an increase in the cytosolic cAMP concentration. Under these conditions, IBMXstimulated GIP secretion was strongly inhibited by coapplication of somatostatin (100 nmol/l) (Fig. 3a). This effect was significantly, although not completely, reversed by SSTR5A (100 nmol/l). Neither somatostatin nor SSTR5A significantly affected GIP secretion under basal conditions in the absence of IBMX (Fig. 3a). Somatostatin (100 nmol/l) similarly abolished IBMX-stimulated GLP-1 secretion in both small and large intestinal cultures (Fig. 3b, c). SSTR5A reversed the inhibitory effect of somatostatin on small intestinal GLP-1 release, and also increased IBMX-triggered secretion in the absence of added somatostatin, suggesting the presence of a basal somatostatin tone that is likely to be due to the presence of somatostatin-secreting D cells in these mixed intestinal cultures (Fig. 3b). Indeed, measured somatostatin levels in control wells were $43 \pm 13$ $\mathrm{pmol} / \mathrm{l}(n=7)$.
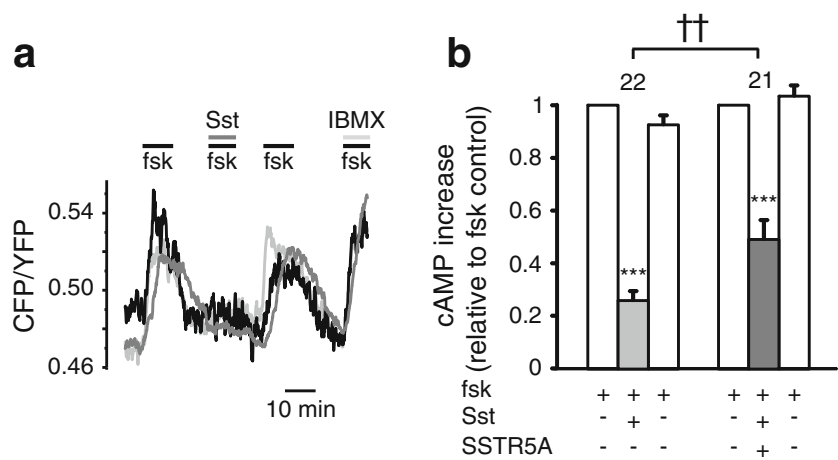

Fig. 2 Somatostatin (Sst) lowers cAMP in the GLUTag cell line. (a) Changes in cAMP concentration in response to $G_{\alpha i}$ activation. GLUTag cells transfected with Epac2-camps were perfused with forskolin (fsk; $2 \mu \mathrm{mol} / \mathrm{l}) \mathrm{with} /$ without Sst $(100 \mathrm{nmol} / \mathrm{l}$ ), followed by fsk/IBMX (10 and $100 \mu \mathrm{mol} / 1$ respectively) as indicated. CFP and YFP emission was monitored in response to excitation with $435 / 10 \mathrm{~nm}$. Three traces, each representing the CFP/YFP ratio of a single cell, are shown. (b) Mean changes in the CFP/YFP emission ratio in response to application of forskolin $(2 \mu \mathrm{mol} / \mathrm{l})$, Sst $(100 \mathrm{nmol} / \mathrm{l})$ or SSTR5A $(100 \mathrm{nmol} / \mathrm{l})$ in experiments performed as in (a). Responses to fsk/Sst, fsk/Sst/SSTR5A and the final application of fsk alone were normalised to the response triggered by the first application of fsk in the same cell. Data are means and error bars show 1 SEM, with the number of cells (monitored in between five and seven independent experiments per condition) indicated above each bar. Statistical significance was assessed by one-way ANOVA with post hoc Bonferroni test: $* * * p<0.001$ compared with first application of fsk and ${ }^{\dagger \dagger} p<0.01$ comparing the Sst response in the absence/ presence of SSTR5A

High expression of the endocannabinoid receptor Cnrl in $K$ cells Mining the microarray data for other $\mathrm{G}_{\alpha \mathrm{i}}$-coupled receptors, we observed high expression in $\mathrm{K}$ cells but not controls for the probe against $\mathrm{Cnrl}$ (encoding the endocannabinoid receptor CB1) (Fig. 4a). This was also detected in small intestinal, but not colonic, L cells (Fig. 4a). Very little expression was observed for $C n r 2$, encoding the related cannabinoid receptor CB2. By quantitative RT-PCR (Fig. 4b, c), Cnrl but not $C n r 2$ expression was similarly found to be enriched in small intestinal $\mathrm{K}$ and $\mathrm{L}$ cells, but appeared to be absent from colonic L cells. Although Cnrl expression appeared higher in $\mathrm{K}$ than $\mathrm{L}$ cells, this did not reach statistical significance.

CB1 receptor activation inhibits GIP but not GLP-1 secretion in vitro To assess the functional expression of $\mathrm{CB} 1$, we tested the effect of the CB1 receptor agonist mAEA $(10 \mu \mathrm{mol} / \mathrm{l})$ on basal and IBMX-stimulated GIP release in primary small intestinal cultures. mAEA did not affect basal GIP release but strongly inhibited secretion triggered by IBMX (Fig. 5a). This effect of mAEA was significantly attenuated by the concomitant presence of the $\mathrm{CB} 1$-specific inverse agonist AM251 $(1 \mu \mathrm{mol} / \mathrm{l})$. AM251 alone did not significantly increase basal or IBMX-stimulated GIP secretion. As Cnrl was also detected in small intestinal L cells, we assessed whether mAEA inhibited GLP-1 secretion in primary cultures 


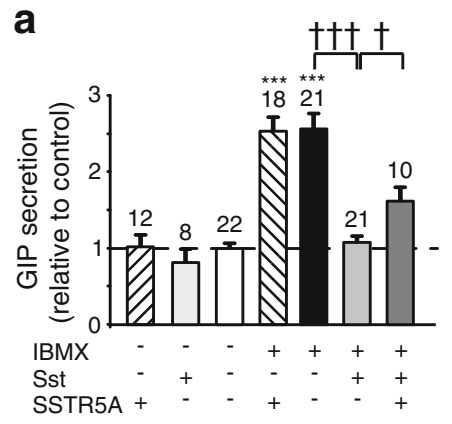

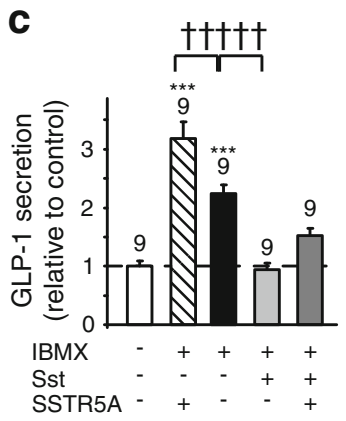

Fig. 3 Inhibition of IBMX-stimulated GIP and GLP-1 secretion by somatostatin (Sst). (a) GIP secretion from primary small intestinal cultures treated with IBMX $(100 \mu \mathrm{mol} / \mathrm{l})$ with/without Sst $(100 \mathrm{nmol} / \mathrm{l})$ and SSTR5A (100 nmol/1), as indicated. (b,c) GLP-1 secretion from primary small intestinal (b) and colonic (c) cultures treated with IBMX $(100 \mu \mathrm{mol} / \mathrm{l})$ with or without Sst $(100 \mathrm{nmol} / \mathrm{l})$ and SSTR5A $(100 \mathrm{nmol} / \mathrm{l})$, as indicated. Data are expressed relative to the basal secretory rate measured in parallel on the same day. Data are means \pm SEM of the number of wells indicated above each bar. Statistical significance was assessed by one-way ANOVA with post hoc Bonferroni test: ** $p<0.01$, ${ }^{* * *} p<0.001$ compared with control; ${ }^{\dagger} p<0.05,{ }^{\dagger \dagger} p<0.01,{ }^{\dagger \dagger} p<0.001$ between conditions as indicated from the small intestine and colon. Contrary to the observed expression of Cnrl in small intestinal L cells, we observed no effect of the CB1 ligands on IBMX-stimulated GLP-1 secretion from the small intestine (Fig. 5b, c). GLP-1 secretion from colonic cultures was also not affected by mAEA or AM251.

Although no effect of mAEA was found on GLP-1 secretion from L cells in primary culture, GLUTag cells were tested as a potential cell line model for investigating the effects of CB1 ligands on cAMP levels, as they expressed mRNA for Cnrl (see Fig. 4b). Partial inhibition of IBMXstimulated GLP-1 secretion by mAEA was observed in GLUTag cells, which was sensitive to AM251 (Fig. 5d). Recordings using Epac2-camps (Fig. 5e, f) showed that mAEA resulted in a small but significant reduction in forskolin-triggered cAMP responses, which did not reverse on washout. Co-application of AM251 prevented the effect of mAEA, supporting the idea that this represents a CB1mediated effect.
Effects of CB1 ligands on incretin hormone secretion in vivo Finally, we assessed whether mAEA or AM251 could modulate basal or glucose-triggered GIP secretion in vivo. mAEA or AM251 (or vehicle controls) was administered intraperitoneally to fasted rats, and after taking blood samples a glucose bolus (dose) was given by gavage $30 \mathrm{~min}$ later. In the fasting state, GIP levels were not significantly altered by mAEA (Fig. 6a) or either of the vehicle controls (DMSO or Tocrisolve; Fig. 6b), but were increased from $34 \pm 4$ to $39 \pm 4 \mathrm{pmol} / 1$ by AM251 (Fig. 6c; $p=0.04$ ), suggesting that basal GIP secretion is suppressed by an inhibitory cannabinoid tone. Basal GLP-1 concentrations were not affected by mAEA, AM251 or vehicle controls. Following the glucose gavage, mAEA resulted in lower plasma GIP levels (Fig. 6d,e), but did not affect concentrations of GLP-1, insulin or glucose (Fig. 6f-i). Acetaminophen, which was included in the orally administered glucose solution to monitor gastric emptying, did not appear with a significantly different time course in the

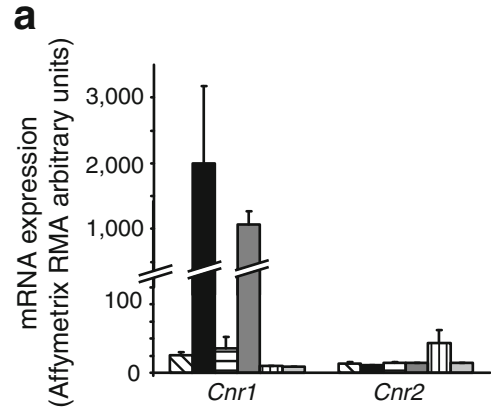

Fig. 4 Expression of endocannabinoid receptors in enteroendocrine cells. (a) Mean microarray RMA intensities for probes against $\mathrm{Cnrl}$ and $C n r 2$ in $\mathrm{K}$ cells $(\mathrm{K}+$, black bars), small intestinal and colonic $\mathrm{L}$ cells $(\mathrm{L}+$, dark grey bars; $\mathrm{LC}+$, light grey bars, respectively), and non-fluorescent control cells from the same tissue preparations ( $\mathrm{K}$-, diagonal hatching; $\mathrm{L}-$, horizontal hatching; $\mathrm{LC}-$, vertical hatching) ( $n=2-3$ each). (b,c) Relative expression of Cnrl (b) andCnr2 (c) b

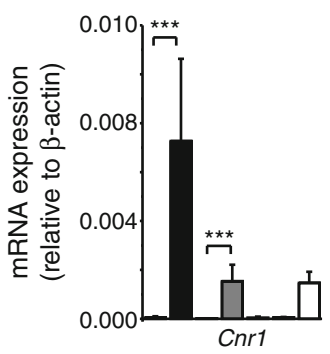

mRNA relative to $\beta$-actin assessed by RT-PCR in FACS-sorted cell populations labelled as in (a), together with GLUTag cells (white bar). Data are presented as the geometric mean and upper SEM ( $n>3$ each). Significance comparisons between $\mathrm{K}+$ and $\mathrm{K}-$, $\mathrm{L}+$ and $\mathrm{L}-$, and $\mathrm{K}+$ and $\mathrm{L}+$ cells were calculated by one-way ANOVA with post hoc Bonferroni test performed on the $\log ($ base 2$)$ data: $* * * p<0.001$ 


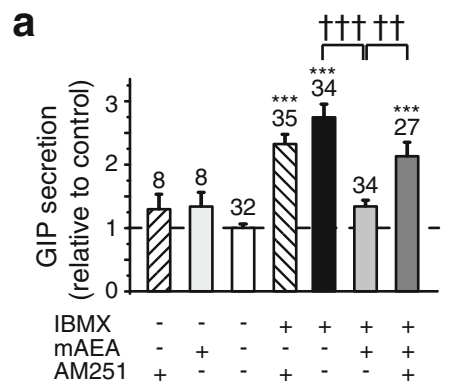

b

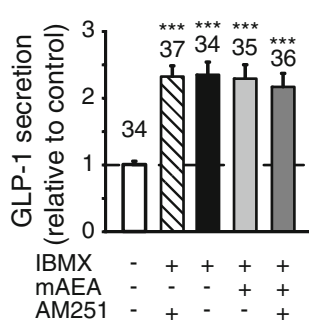

C

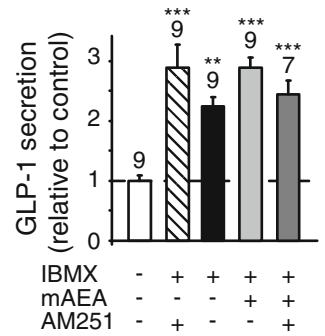

d

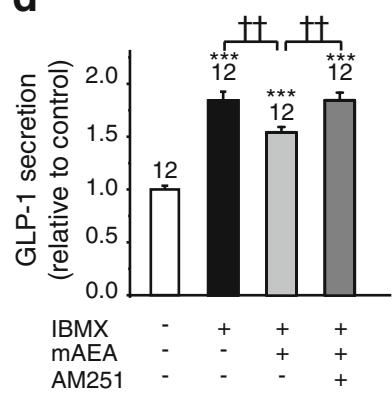

Fig. 5 Effects of CB1 ligands on K and L cells. (a) GIP secretion from primary small intestinal cultures treated with IBMX $(100 \mu \mathrm{mol} / \mathrm{l})$, mAEA $(10 \mu \mathrm{mol} / \mathrm{l})$ and AM251 $(1 \mu \mathrm{mol} / \mathrm{l})$, as indicated. (b, c) GLP1 secretion from primary small intestinal (b) and colonic (c) cultures treated with IBMX $(100 \mu \mathrm{mol} / \mathrm{l}), \mathrm{mAEA},(10 \mu \mathrm{mol} / \mathrm{l})$ and AM251 $(1 \mu \mathrm{mol} / \mathrm{l})$, as indicated. In $(\mathbf{a}-\mathbf{c})$ Data are expressed relative to the basal secretory rate measured in parallel on the same day. Data represent the means \pm SEM of the number of wells indicated above each bar. Statistical significance was assessed by one-way ANOVA with post hoc Bonferroni test: $* * p<0.01, * * * p<0.001$ compared with control buffer; ${ }^{\dagger \dagger} p<0.01,{ }^{\dagger \dagger} p<0.001$ between conditions as indicated. (d) GLP-1 secretion from GLUTag cells treated with IBMX $(100 \mu \mathrm{mol} / \mathrm{l})$, $\mathrm{mAEA}(10 \mu \mathrm{mol} / \mathrm{l})$ and AM251 $(1 \mu \mathrm{mol} / \mathrm{l})$, as indicated. GLP-1 secretion is expressed relative to the basal secretion measured in parallel on the same day. Data are means \pm SEM of the number of wells indicated above each bar. Statistical significance was assessed by one-way ANOVA with post hoc Bonferroni test: ${ }^{* *} p<0.001$ compared with control; ${ }^{\dagger \dagger} p<0.01$

mAEA-treated group (Fig. 6j). Contrary to our prediction, AM251-treated animals had lower plasma GIP and insulin concentrations and correspondingly higher $30 \mathrm{~min}$ plasma glucose levels after glucose gavage than their corresponding control group (see electronic supplementary material [ESM] Fig. 1). However, the plasma acetaminophen concentrations indicated a significant slowing of gastric emptying in the AM251-treated group, which would result in reduced glucose delivery to the duodenal $\mathrm{K}$ cells. In the context of the resulting smaller luminal glucose stimulus, it is not possible to interpret whether endogenous cannabinoid levels affected glucosetriggered GIP release.

\section{Discussion}

We demonstrate here that GIP release can be inhibited through the recruitment of $\mathrm{G}_{\alpha \mathrm{i}}$-coupled receptors. Most importantly, between conditions. (e) GLUTag cells transfected with Epac2-camps were perfused with forskolin (fsk; $2 \mu \mathrm{mol} / \mathrm{l}$ ) with or without mAEA (10 $\mu \mathrm{mol} / \mathrm{l})$, followed by fsk/IBMX (10 and $100 \mu \mathrm{mol} / 1$ respectively), as indicated. CFP and YFP emission was monitored in response to excitation with $435 / 10 \mathrm{~nm}$. Three traces, each representing the CFP/ YFP ratio of a single cell, are shown. (f) Mean changes in the CFP/YFP emission ratio in response to application of fsk, mAEA or AM251 $(1 \mu \mathrm{mol} / \mathrm{l})$, in experiments performed as in (e). Responses to fsk/mAEA, fsk/mAEA/AM251 and the final application of fsk alone were normalised to the response triggered by the first application of fsk in the same cell. Data are means and error bars show 1 SEM with the number of cells (monitored in between five and seven independent experiments per condition) indicated above each bar. Statistical significance was assessed by one-way ANOVA with post hoc Bonferroni test: ${ }^{* *} p<0.01,{ }^{* * *} p<$ 0.001 compared with first application of fsk; ${ }^{\dagger} p<0.05$ comparing the mAEA response in the absence and presence of AM251

CB1 receptor stimulation suppresses GIP but not GLP-1 secretion. Expression of cannabinoid receptors has, to our knowledge, not previously been reported in enteroendocrine cells, yet our expression analysis identified the CB1 receptor message ( $\mathrm{Cnrl}$ ) as one of the highest expressed G-proteincoupled receptor mRNAs in FACS-purified K cells. Consistent with this observation, GIP secretion was inhibited by the CB1 receptor agonist mAEA in vitro, an effect partly reversed by co-application of the inverse agonist AM251.

As expected, we observed a robust inhibition of both GIP and GLP-1 secretion in vitro by somatostatin. A suppressive effect of somatostatin on incretin secretion has long been known. Consistent with the predominant $\mathrm{G}_{\alpha \mathrm{i}}$ coupling of SSTRs, somatostatin suppressed cytosolic cAMP responses in the GLUTag cell line, at least in part via SSTR5. A role for SSTR5 in primary murine $\mathrm{K}$ and $\mathrm{L}$ cells was also evident from secretion studies in primary intestinal cultures. Additional roles for SSTR2 and SSTR3 in both cell types are 
a

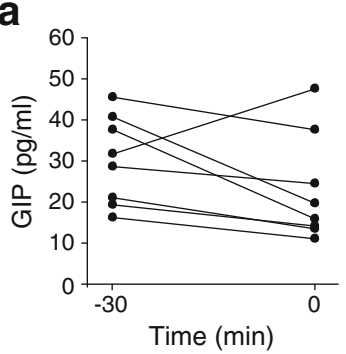

d

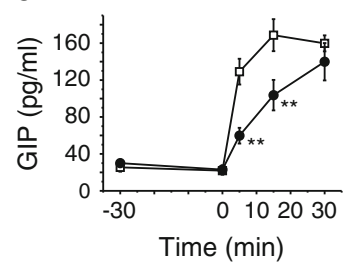

h

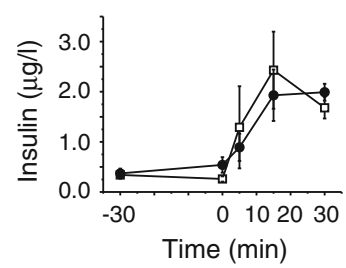

b

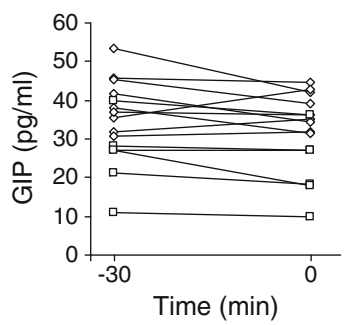

f
C

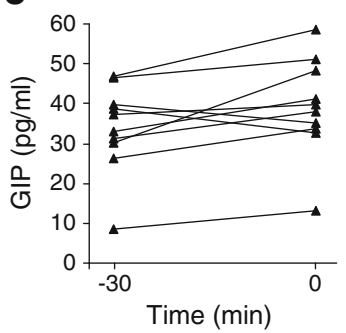

e

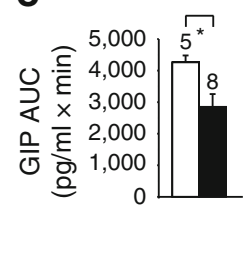

i

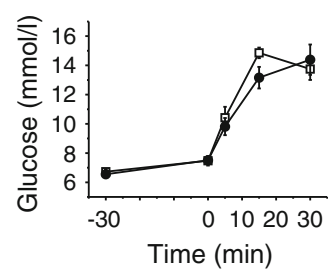

$\mathbf{g}$

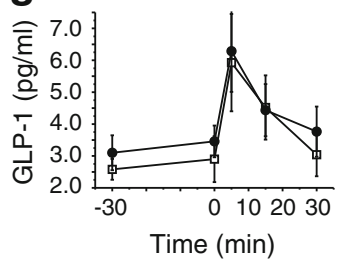

j

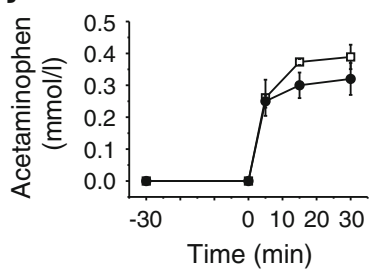

Fig. 6 Effects of CB1 ligands on hormone secretion in vivo. (a-c) Plasma GIP levels in individual rats treated at -30 min with mAEA (a), vehicle control (squares represent controls for mAEA, diamonds represent controls for AM251) (b), or AM251 (c). Samples at 0 min were taken immediately prior to glucose gavage. $(\mathbf{d}-\mathbf{j})$ Plasma profiles for GIP (d), GLP-1 (g), insulin (h), glucose (i) and acetaminophen (j), and area under the curve (AUC) for GIP (e) or GLP-1 (f), following i.p. administration of mAEA (black circles and black bars; $n=8$ ) or vehicle control (white squares and open bars; $n=5$ ) at $-30 \mathrm{~min}$ and glucose/ acetaminophen gavage at $0 \mathrm{~min}$. Data are means $\pm 1 \mathrm{SEM}$ of the plasma concentrations observed at the times indicated. Statistical significance was assessed in (d) and ( $\mathbf{g}-\mathbf{j})$ by two-way ANOVA with post hoc Bonferroni test $(* * p<0.01$ vs vehicle control) and in (e) and (f) by unpaired Student's $t$ test $\left({ }^{*} p<0.05\right)$ suggested by the mRNA expression data and the incomplete suppression of the inhibitory effect of somatostatin by the SSTR5 antagonist. This is in agreement with a previous report that GLP-1 secretion from fetal rat intestinal cultures was suppressed by specific agonists of SSTRs in the rank order SSTR5 $>$ SSTR 2>SSTR 3 [22].

Although we detected mRNA expression of $\mathrm{Cnrl}$ in small intestinal $L$ cells, we observed no inhibition of GLP-1 secretion from primary cultures by mAEA. The CB1-dependent inhibition of GIP but not GLP-1 release did not reflect interexperimental variability as the difference was still observed when supernatant fractions from the same wells were analysed for both incretins. A lack of effect of mAEA on GLP-1 secretion was also observed in colonic cultures, consistent with the absence of $\mathrm{Cnrl}$ expression in purified colonic L cells. We thus conclude that the observed Cnrl mRNA expression in small intestinal L cells either does not translate into a sufficient density of functional receptors or reflects only a minority of $\mathrm{L}$ cells. In this context, it is interesting to note that there is an established overlap in the small intestinal $\mathrm{K}$ and $\mathrm{L}$ cell populations, with up to $20 \%$ of L cells also expressing GIP [23-25].
Under in vitro conditions, the inverse CB1 agonist AM251 did not enhance basal or IBMX-triggered GIP secretion in the absence of an exogenous CB1 receptor agonist. This indicates that there is no significant constitutive activity of $\mathrm{CB} 1$ receptors in $\mathrm{K}$ cells capable of overcoming a rise in cAMP in the presence of phosphodiesterase inhibition. Interestingly, however, the SSTR5 antagonist also failed to enhance GIP secretion from small intestinal cultures in the absence of added somatostatin, despite the evident somatostatin tone in the same cultures as demonstrated by the doubling of GLP-1 release under the same conditions. Indeed, the measured somatostatin concentration of approximately $50 \mathrm{pmol} / \mathrm{l}$ in supernatant fractions from small intestinal cultures is close to the reported affinity of rodent SSTR5 ( $K_{\mathrm{d}} 50-300 \mathrm{pmol} / 1$ [26]). Endogenously released somatostatin was also reported to block GIP release in canine intestinal cultures enriched by elutriation for endocrine cells [21]. As the SSTR5 antagonist was capable of partially reversing the inhibition of GIP secretion by exogenously applied somatostatin, it is possible that the observed GIP secretion in the presence of IBMX represents a maximal stimulation of $\mathrm{K}$ cells under our culture conditions. 
The expression of $\mathrm{Cnrl}$ and in vitro effects of CB1 ligands on GIP release were reflected by our in vivo observations in rats, which showed that GIP but not GLP-1 responses to an OGTT were reduced by mAEA pretreatment. As endocannabinoids are known to inhibit gastric emptying [27], a trivial explanation for the observed delayed appearance of GIP in the plasma could have been a slowed transit of glucose into the duodenum. This seems an unlikely explanation for our findings, however, as we observed no significant differences in the time courses of glucose, acetaminophen and GLP-1 appearance in the plasma between the two groups. It thus appears likely that direct CB1-dependent inhibition of $\mathrm{K}$ cells at least in part underlies the reduction in the GIP response caused by mAEA in vivo. In a similar experiment to determine the in vivo effect of AM251, GIP levels were found to increase in the fasting state, but it was not possible to assess endogenous CB1 tone after a glucose challenge because AM251 unexpectedly slowed gastric emptying. This is likely to have reduced glucose delivery to the duodenal $\mathrm{K}$ cells, accounting for the observed lower plasma GIP and insulin levels, and correspondingly higher plasma glucose concentration at $30 \mathrm{~min}$.

In the stomach and small intestine of rodents, arachidonylethanolamide and, in some but not all studies, the related endocannabinoid 2-arachidonyl-glycerol have been reported to increase in concentration upon fasting, with levels returning to baseline within an hour of refeeding [28-30]. Intestinally generated endocannabinoids are thought to exert orexigenic effects by signalling through vagal afferent neurons to satiety centres in the central nervous system (CNS) $[27,30]$. The stimulatory effect of systemic cannabinoids on feeding is, however, believed to depend mostly on CB1 receptor activation in the CNS [31]. Rimonabant, an inverse agonist at the CB1 receptor, was used clinically for the treatment of obesity due to its anorectic effects, but was withdrawn from the market because of psychological side effects, including depression and increased suicidal thoughts [32].

Although most effects of rimonabant on feeding are mirrored in a mouse with CNS-restricted CB1 receptor knockout [33], there is still considerable interest in developing drugs targeting peripheral cannabinoid receptors for the treatment of obesity [27,31]. Our results suggest that an additional effect of antagonising peripheral $\mathrm{CB} 1$ receptors may be to increase GIP secretion. Although this may beneficially enhance the incretin effect, GIP is thought to promote storage of energy resources in peripheral tissues, possibly due to direct effects on adipocytes $[34,35]$. This would potentially oppose the beneficial effects of CB1 receptor antagonism on body weight, although it should be noted that the effect of GIP on nutrient storage is controversial, with some laboratories reporting lipolytic actions on adipocyte models in vitro [36]. Indeed, in humans, GIP had only minor effects on triacylglycerol clearance that became evident only under conditions of a hyperglycaemic hyperinsulinaemic clamp [37].
The multiple roles of the endocannabinoid system, both peripherally and centrally, have made CB1 a difficult receptor to target successfully for the therapy of diabetes and obesity [32]. Our results suggest that there is a small but significant $\mathrm{CB} 1$-dependent inhibition of $\mathrm{K}$ cells during fasting that might serve to increase the sensitivity to feedingrelated signals, as the postprandial reduction in endocannabinoid levels would activate $\mathrm{K}$ cells in concert with nutrient stimuli arriving in the duodenal lumen. Regulation of GIP secretion by the endocannabinoid system could be envisaged as part of the transition from a preprandial to a postprandial metabolic state. Although the rate of delivery of glucose to the duodenum appears to provide a dominant degree of control over $\mathrm{K}$ cell secretion, as evident from the in vivo experiments with AM251, CB1 activation might provide a useful tool to dissociate GIP and GLP-1 secretion.

Acknowledgements We thank K. Burling and the MRC-CORD for performing plasma assays for GLP-1, insulin and acetaminophen and G. Yeo (MRC-CORD) for assistance with microarray analysis. B. Moss provided assistance with RT-PCRs during a work experience placement. D. Drucker (Samuel Lunenfeld Research Institute, Toronto, Canada) and M. Lohse (University of Wuerzburg, Germany) kindly provided the GLUTag cell line and Epac2-camps sensor, respectively.

Funding This work was funded by Wellcome Trust Senior Research Fellowships to FMG and FR (WT088357 and WT084210) and Studentship to WJM. CEM is funded by a BBSRC/AstraZeneca Case Studentship. EOB is supported by a Yousef Jameel Scholarship. Animal maintenance and plasma assays were funded in part by MRC Centre for Obesity and Related Disorders (MRC-CORD, Cambridge, UK).

Duality of interest The authors declare that there is no duality of interest associated with this manuscript. Hoffmann-La Roche, which provided SSTR5A, was not involved in either study design or data analysis, but was given access to the manuscript pre-publication in line with the MTA.

Contribution statement CEM, WJM, HEP, EOB, CHR, AMH and MLE researched the data. MLE, FMG and FR designed the study and FMG and FR drafted the manuscript. All authors contributed to revision of the manuscript and approved the final version.

Open Access This article is distributed under the terms of the Creative Commons Attribution Noncommercial License which permits any noncommercial use, distribution, and reproduction in any medium, provided the original author(s) and the source are credited.

\section{References}

1. Baggio LL, Drucker DJ (2007) Biology of incretins: GLP-1 and GIP. Gastroenterology 132:2131-2157

2. Miyawaki K, Yamada Y, Yano H et al (1999) Glucose intolerance caused by a defect in the entero-insular axis: a study in gastric inhibitory polypeptide receptor knockout mice. Proc Natl Acad Sci U S A 96:14843-14847 
3. Miyawaki K, Yamada Y, Ban N et al (2002) Inhibition of gastric inhibitory polypeptide signaling prevents obesity. Nat Med 8:738-742

4. Irwin N, Flatt PR (2009) Evidence for beneficial effects of compromised gastric inhibitory polypeptide action in obesity-related diabetes and possible therapeutic implications. Diabetologia 52:1724-1731

5. Althage MC, Ford EL, Wang S, Tso P, Polonsky KS, Wice BM (2008) Targeted ablation of glucose-dependent insulinotropic polypeptideproducing cells in transgenic mice reduces obesity and insulin resistance induced by a high fat diet. J Biol Chem 283:18365-18376

6. Kieffer TJ (2003) GIP or not GIP? That is the question. Trends Pharmacol Sci 24:110-112

7. Buchan AM, Polak JM, Capella C, Solcia E, Pearse AG (1978) Electronimmunocytochemical evidence for the $\mathrm{K}$ cell localization of gastric inhibitory polypeptide (GIP) in man. Histochemistry 56:37-44

8. Buffa R, Polak JM, Pearse AG, Solcia E, Grimelius L, Capella C (1975) Identification of the intestinal cell storing gastric inhibitory peptide. Histochemistry 43:249-255

9. Diakogiannaki E, Gribble FM, Reimann F (2012) Nutrient detection by incretin hormone secreting cells. Physiol Behav 106:387-393

10. Gorboulev V, Schürmann A, Vallon V et al (2012) Na+-D-glucose cotransporter SGLT1 is pivotal for intestinal glucose absorption and glucose-dependent incretin secretion. Diabetes 61:187-196

11. Parker HE, Habib AM, Rogers GJ, Gribble FM, Reimann F (2009) Nutrient-dependent secretion of glucose-dependent insulinotropic polypeptide from primary murine $\mathrm{K}$ cells. Diabetologia 52:289-298

12. Hansen KB, Rosenkilde MM, Knop FK et al (2011) 2-Oleoyl glycerol is a GPR119 agonist and signals GLP-1 release in humans. J Clin Endocrinol Metab 96:E1409-E1417

13. Parker HE, Reimann F, Gribble FM (2010) Molecular mechanisms underlying nutrient-stimulated incretin secretion. Expert Rev Mol Med 12:e1

14. Reimann F, Habib AM, Tolhurst G, Parker HE, Rogers GJ, Gribble FM (2008) Glucose sensing in L cells: a primary cell study. Cell Metab 8:532-539

15. Nikolaev VO, Bünemann M, Hein L, Hannawacker A, Lohse MJ (2004) Novel single chain cAMP sensors for receptor-induced signal propagation. J Biol Chem 279:37215-37218

16. Friedlander RS, Moss CE, Mace J et al (2011) Role of phosphodiesterase and adenylate cyclase isozymes in murine colonic glucagonlike peptide 1 secreting cells. Br J Pharmacol 163:261-271

17. Osundiji MA, Zhou L, Shaw J et al (2010) Brain glucosamine boosts protective glucoprivic feeding. Endocrinology 151:1499-1508

18. Järbe TU, Liu Q, Makriyannis A (2006) Antagonism of discriminative stimulus effects of delta(9)-THC and (R)-methanandamide in rats. Psychopharmacology (Berl) 184:36-45

19. McLaughlin PJ, Winston K, Swezey L et al (2003) The cannabinoid CB1 antagonists SR 141716A and AM 251 suppress food intake and food-reinforced behavior in a variety of tasks in rats. Behav Pharmacol 14:583-588

20. Sprecher U, Mohr P, Martin RE et al (2010) Novel, non-peptidic somatostatin receptor subtype 5 antagonists improve glucose tolerance in rodents. Regul Pept 159:19-27
21. Kieffer TJ, Buchan AM, Barker H, Brown JC, Pederson RA (1994) Release of gastric inhibitory polypeptide from cultured canine endocrine cells. Am J Physiol 267:E489-E496

22. Chisholm C, Greenberg GR (2002) Somatostatin-28 regulates GLP-1 secretion via somatostatin receptor subtype 5 in rat intestinal cultures. Am J Physiol Endocrinol Metab 283:E311-E317

23. Mortensen K, Christensen LL, Holst JJ, Orskov C (2003) GLP-1 and GIP are colocalized in a subset of endocrine cells in the small intestine. Regul Pept 114:189-196

24. Theodorakis MJ, Carlson O, Michopoulos S et al (2006) Human duodenal enteroendocrine cells: source of both incretin peptides, GLP-1 and GIP. Am J Physiol Endocrinol Metab 290:E550-E559

25. Habib AM, Richards P, Cairns LS et al (2012) Overlap of endocrine hormone expression in the mouse intestine revealed by transcriptional profiling and flow cytometry. Endocrinology 153:3054-3065

26. O'Carroll AM, Raynor K, Lolait SJ, Reisine T (1994) Characterization of cloned human somatostatin receptor SSTR5. Mol Pharmacol 46:291-298

27. Izzo AA, Sharkey KA (2010) Cannabinoids and the gut: new developments and emerging concepts. Pharmacol Ther 126:21-38

28. Izzo AA, Piscitelli F, Capasso R et al (2009) Peripheral endocannabinoid dysregulation in obesity: relation to intestinal motility and energy processing induced by food deprivation and refeeding. Br J Pharmacol 158:451-461

29. Petersen G, Sørensen C, Schmid PC et al (2006) Intestinal levels of anandamide and oleoylethanolamide in food-deprived rats are regulated through their precursors. Biochim Biophys Acta 1761:143-150, discussion 141-142

30. Gómez R, Navarro M, Ferrer B et al (2002) A peripheral mechanism for CB1 cannabinoid receptor-dependent modulation of feeding. J Neurosci 22:9612-9617

31. Quarta C, Mazza R, Obici S, Pasquali R, Pagotto U (2011) Energy balance regulation by endocannabinoids at central and peripheral levels. Trends Mol Med 17:518-526

32. Butler H, Korbonits M (2009) Cannabinoids for clinicians: the rise and fall of the cannabinoid antagonists. Eur $\mathrm{J}$ Endocrinol 161:655-662

33. Pang Z, Wu NN, Zhao W et al (2011) The central cannabinoid $\mathrm{CB} 1$ receptor is required for diet-induced obesity and rimonabant's antiobesity effects in mice. Obesity (Silver Spring) 19:19231934

34. Yip RG, Boylan MO, Kieffer TJ, Wolfe MM (1998) Functional GIP receptors are present on adipocytes. Endocrinology 139:4004-4007

35. Hauner H, Glatting G, Kaminska D, Pfeiffer EF (1988) Effects of gastric inhibitory polypeptide on glucose and lipid metabolism of isolated rat adipocytes. Ann Nutr Metab 32:282-288

36. McIntosh CH, Bremsak I, Lynn FC et al (1999) Glucosedependent insulinotropic polypeptide stimulation of lipolysis in differentiated 3 T3-L1 cells: wortmannin-sensitive inhibition by insulin. Endocrinology 140:398-404

37. Asmar M, Simonsen L, Madsbad S, Stallknecht B, Holst JJ, Bülow J (2010) Glucose-dependent insulinotropic polypeptide may enhance fatty acid re-esterification in subcutaneous abdominal adipose tissue in lean humans. Diabetes 59:2160-2163 